\title{
Green tea extract suppresses adiposity and affects the expression of lipid metabolism genes in diet-induced obese zebrafish
}

Takahiro Hasumura', Yasuhito Shimada $2,3,4,5$, Junya Kuroyanagi ${ }^{2}$, Yuhei Nishimura ${ }^{2,3,4,5}$, Shinichi Meguro ${ }^{1}$, Yoshinori Takema ${ }^{6}$ and Toshio Tanaka $a^{2,3,4,5^{*}}$

\begin{abstract}
Background: Visceral fat accumulation is one of the most important predictors of mortality in obese populations. Administration of green tea extract (GTE) can reduce body fat and reduce the risk of obesity-related diseases in mammals. In this study, we investigated the effects and mechanisms of GTE on adiposity in diet-induced obese (DIO) zebrafish.

Methods: Zebrafish at 3.5 to 4.5 months post-fertilization were allocated to four groups: non-DIO, DIO, $\mathrm{DIO}+0.0025 \% \mathrm{GTE}$, and $\mathrm{DIO}+0.0050 \% \mathrm{GTE}$. The non-DIO group was fed freshly hatched Artemia once daily $(5 \mathrm{mg}$ cysts/fish daily) for 40 days. Zebrafish in the three DIO groups were fed freshly hatched Artemia three times daily (60 mg cysts/fish daily). Zebrafish in the DIO +0.0025\%GTE and DIO + 0.0050\%GTE groups were exposed to GTE after the start of feeding three times daily for 40 days.
\end{abstract}

Results: Three-dimensional microcomputed tomography analysis showed that GTE exposure significantly decreased the volume of visceral but not subcutaneous fat tissue in DIO zebrafish. GTE exposure increased hepatic expression of the lipid catabolism genes ACOX1 (acyl-coenzyme A oxidase 1, palmitoy), ACADM (acyl-coenzyme A dehydrogenase, c-4 to c-12 straight chain), and PPARA (peroxisome proliferator-activated receptor alpha). GTE exposure also significantly decreased the visceral fat expression of SOCS3 (suppressor of cytokine signaling 36 ) which inhibits leptin signaling.

Conclusions: The present results are consistent with those seen in mammals treated with GTE, supporting the validity of studying the effects of GTE in DIO zebrafish. Our results suggest that GTE exerts beneficial effects on adiposity, possibly by altering the expression of lipid catabolism genes and SOCS3.

Keywords: Body fat, Catechin, Diet-induced obesity, 3D micro-computed tomography, Green tea extract, SOCS3, Zebrafish

\section{Background}

According to 2005 World Health Organization estimates, approximately 1.6 billion adults worldwide were overweight (body mass index $[\mathrm{BMI}] \geq 25 \mathrm{~kg} / \mathrm{m}^{2}$ ) and at least 400 million were obese $\left(\mathrm{BMI} \geq 30 \mathrm{~kg} / \mathrm{m}^{2}\right)$, and these numbers are expected to reach 2.3 billion and 700 million,

\footnotetext{
* Correspondence: tanaka@doc.medic.mie-u.ac.jp

${ }^{2}$ Department of Molecular and Cellular Pharmacology, Pharmacogenomics and Pharmacoinformatics, Mie University Graduate School of Medicine, 2-174 Edobashi, Tsu, Mie 514-8507, Japan

${ }^{3}$ Department of Bioinformatics, Mie University Life Science Research Center, 2-174 Edobashi, Tsu, Mie 514-8507, Japan

Full list of author information is available at the end of the article
}

respectively, by 2015 [1]. It is widely accepted that obesity results from a positive energy balance [2]. In general, obesity can be classified into visceral and subcutaneous types according to the distribution of fat. Visceral obesity accompanies or precedes components of the metabolic syndrome, such as hyperinsulinemia and insulin resistance [3]. Consequently, visceral fat accumulation is an independent predictor of mortality in men [4].

Green tea, one of the most popular beverages in Asian countries, contains numerous polyphenols known as catechins, particularly epigallocatechin gallate, epicatechin gallate, and gallocatechin gallate. Tea and tea components 
have many beneficial properties, including antioxidant [5], anticancer [6,7], antidiabetic [8], and anti-atherogenic [9] activities. Moreover, intake of tea catechins inhibits dietinduced obesity (DIO) in mice [10,11] and reduces body weight and body fat in humans [12-17]. These anti-obesity effects of tea catechins seem to involve stimulation of fat oxidation [10,18,19], modulation of adipogenesis [20], decreased fat synthesis [6,20-22], and inhibition of digestive enzyme activity and nutrient absorption [8].

Zebrafish (Danio rerio) are vertebrates, and their organs and tissues show similarities to those of humans in terms of their structure and function. Consequently, zebrafish are increasingly being used as models of human diseases [12,23-25] because of their ease of genetic manipulation and their economic potential for use in breeding and testing. In addition, lipid metabolism in zebrafish is very similar to that in humans in terms of intestinal absorption with the aid of bile produced in the liver [26], transport of fat and cholesterol by lipoproteins [27], $\beta$-oxidation [28], and storage as triacylglycerols in visceral, subcutaneous, and intramuscular adipocyte depots [26,29]. Because of these similarities and advantages, zebrafish are used in lipid metabolism research as a model for lipid-related diseases, including atherosclerosis induced by high-cholesterol diets [30] and obesity induced by overexpression of the endogenous melanocortin antagonist agouti-related protein (AgRP) [29]. Moreover, Oka et al. demonstrated the usefulness of a zebrafish model of DIO that shares common pathophysiological pathways with mammalian obesity [31]. DIO zebrafish have also been used to validate the antiobesity effects of natural products [32].

Here, we investigated the effects of green tea extract (GTE) on body weight, visceral and subcutaneous fat accumulation, and the expression of lipid metabolism genes in the liver and visceral fat in DIO zebrafish.

\section{Methods}

\section{Ethical approval}

This study conformed to the ethical guidelines established by the Institutional Animal Care and Use Committee of Mie University.

\section{GTE}

GTE was prepared and analyzed as previously described [33]. In brief, green tea leaves (Camellia sinensis) were soaked in hot water and the resulting extract was reduced to a powder by spray drying. The extract was then dissolved in hot water and mixed with an equal volume of chloroform. The aqueous phase was recovered with three volumes of ethanol and the extract was freeze-dried after removing the solvent. The composition of catechins was measured by high-performance liquid chromatography. The total catechin content in the GTE was $79.6 \%-81.8 \%(\mathrm{w} / \mathrm{w}$, the sum of all catechins); this comprised epigallocatechin gallate $(43.6 \%-44.4 \%)$, epigallocatechin $(20.4 \%-20.7 \%)$, epicatechin gallate $(12.0 \%-12.3 \%)$, epicatechin $(8.1 \%-8.3 \%)$, gallocatechin $(6.9 \%-7.0 \%)$, gallocatechin gallate $(4.4 \%)$, and others $(3.7 \%-3.8 \%)$. The caffeine content was $0 \%-0.1 \%$.

\section{Animals}

Male and female zebrafish (AB strain, the Zebrafish International Resource Center, Eugene, OR, USA) were kept at approximately $28^{\circ} \mathrm{C}$ under a 14-h light and 10 -h dark cycle. Water conditions of environmental quality were maintained according to The Zebrafish Book [34].

\section{Experimental design \\ Experiment 1}

Male and female zebrafish at 3.5-4.5 months postfertilization were allocated to four groups (non-DIO, $\mathrm{DIO}$, DIO + 0.0025\%GTE, and DIO + 0.0050\%GTE) with five fish per 1.7-L tank. Zebrafish in the non-DIO (control group) were fed freshly hatched Artemia for $120 \mathrm{~min}$ once a day (5 mg cysts/fish daily) for 40 days. Zebrafish in the three DIO groups were fed freshly hatched Artemia for $120 \mathrm{~min}$ three times daily $(60 \mathrm{mg}$ cysts/fish daily). Zebrafish in the DIO +0.0025\%GTE and $\mathrm{DIO}+0.0050 \% \mathrm{GTE}$ groups were exposed to GTE for $105 \mathrm{~min}$, starting $15 \mathrm{~min}$ after the start of feeding (total exposure, $315 \mathrm{~min} /$ day), three times daily for 40 days. During feeding, the tank water flow was stopped; the water in each tank was replaced with fresh water at the end of feeding. Body weight was measured on days $0,14,20,27,34$, and 40. Body fat volume was measured using three-dimensional microcomputed tomography (3D micro-CT) following euthanasia on the final day of the study.

\section{Experiment 2}

Female zebrafish were allocated to three groups (non$\mathrm{DIO}$, DIO, and $\mathrm{DIO}+0.0050 \% \mathrm{GTE}$ ) with five fish per 1.7-L tank. All groups were fed as described in Experiment 1 for 21 days. After feeding on the final day, the zebrafish were euthanized, immediately transferred into tubes containing $8 \mathrm{~mL}$ of RNAlater (Qiagen, Valencia, $\mathrm{CA}$, USA), and stored at $4^{\circ} \mathrm{C}$ until gene expression analysis.

\section{CT measurement of body fat volume}

Zebrafish were fixed in a stretched position on a sample holder. The 3D micro-CT scan was performed with an in vivo System R_mCT 3D micro-CT scanner (Rigaku Corporation, Tokyo, Japan). The following settings were used: voltage, $90 \mathrm{kV}$; current, $100 \mu \mathrm{A}$; magnification, $\times 4$; slice thickness (scanning width), $50 \mu \mathrm{m}$; and exposure time, 2 min. Images were reconstructed and viewed using $\mathrm{i}$-View type $\mathrm{R}$ software (J. Morita Mfg., Kyoto, 
Japan). The CT images were visualized and analyzed using CTAtlas Metabolic Analysis Ver. 2.03 software (Rigaku Corporation). The Hounsfield unit (HU) value of fat tissue was adjusted to between -350.0 and -145.0 in accordance with the manufacturer's instructions. Measurement of body fat volume was limited to the abdominal cavity, and the initial point of the abdominal cavity was set at the cleithrum (Figure 1A). Body fat was then divided into visceral fat and subcutaneous fat along the ribs (Figure 1B).

\section{RNA extraction and quantitative real-time PCR}

The liver and visceral fat were dissected from the stored fish samples prepared in Experiment 2 and were subjected to RNA extraction. Total RNA was extracted from the livers of fish in all three groups (non-DIO, DIO, and $\mathrm{DIO}+0.0050 \% \mathrm{GTE}$ ) using Isogen (Nippongene, Tokyo, Japan) with combination with cleanup protocol of RNeasy mini kit (Qiagen K.K., Tokyo, Japan). cDNA was synthesized using random primers and SuperScript III Reverse Transcriptase (Invitrogen, Carlsbad, CA, USA). Total RNA was extracted from the visceral fat of fish in the DIO and DIO $+0.0050 \%$ GTE groups using an RNeasy Lipid tissue mini kit (Qiagen) and qualified using an Agilent Bioanalyzer 2100 (Agilent, Santa Clara, CA, USA). Because of poor RNA quality, the samples for two of five fish in the DIO group were excluded.

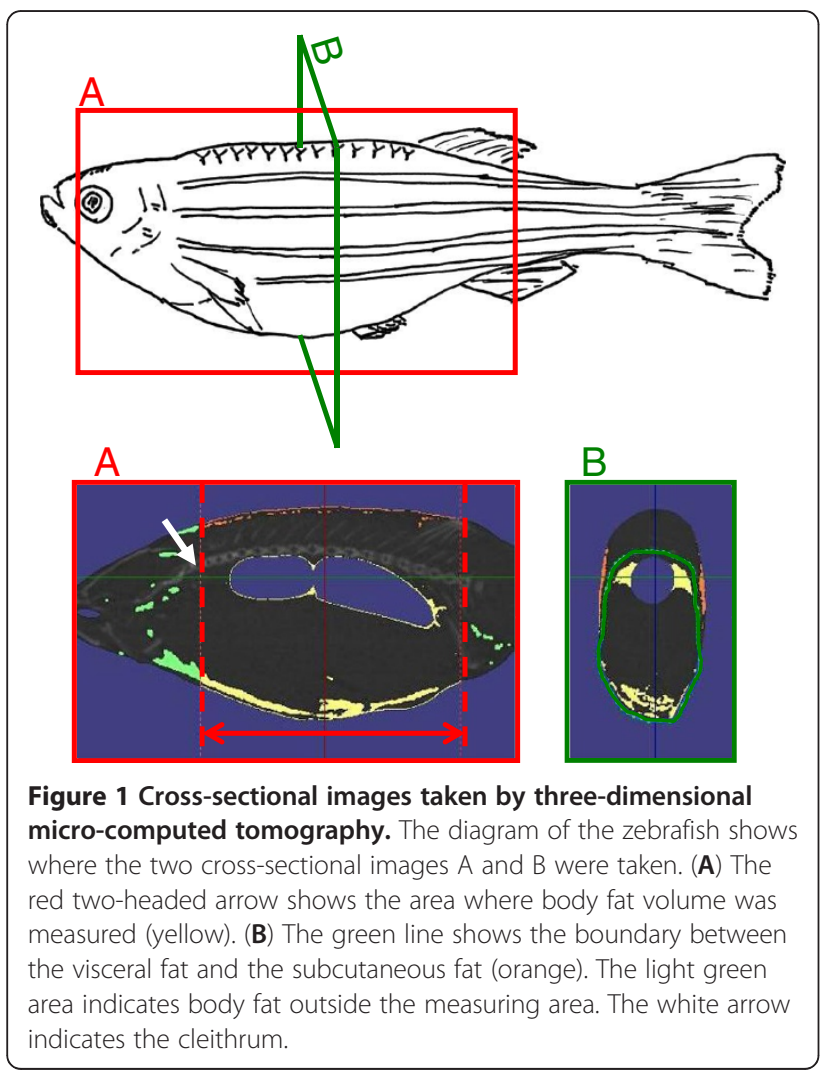

cDNA was synthesized using a High Capacity RNA-tocDNA Kit (Applied Biosystems, Foster City, CA, USA). Total RNA could not be extracted from the visceral fat of fish in the non-DIO group because the amount of visceral fat was too small.

Quantitative real-time PCR was performed on cDNA samples using a TaqMan Fast Universal PCR Master Mix (Applied Biosystems) or Fast SYBR Green Master Mix (Applied Biosystems) and an ABI Prism 7500 Fast Real-Time PCR System (Applied Biosystems) in accordance with the manufacturer's instructions. The TaqMan gene expression assays were as follows: PPIA (peptidylprolyl isomerase Aa; Dr03152038_m1), ACOX1 (acyl-coenzyme A oxidase 1, palmitoyl; Dr03147239_m1), ACADM (Dr03120754_m1), PPARA (peroxisome proliferator-activated receptor alpha $b$; Dr03149883_m1), and SOCS3 (suppressor of cytokine signaling 3b; Dr03203997_s1). The primer sets for SYBR Green were as follows: $A C C$ (acetyl-CoA carboxylase gene, XM_678989, forward primer $\left(5^{\prime}-3^{\prime}\right)$ : ATCATCCCACC CAAACAGAC; reverse primer $\left(3^{\prime}-5^{\prime}\right)$ : CCCATCACA GAAGGTGGAAC) and FASN (fatty acid synthase gene, XM_682295, forward primer $\left(5^{\prime}-3^{\prime}\right)$ : ATCTGTTCCTGTT CGATGGC, reverse primer $\left(3^{\prime}-5^{\prime}\right)$ : AGCATATCTCGGC TGACGTT). The baseline and threshold were set manually in accordance with the manufacturer's instructions. The relative mRNA expression levels were determined using PPIA as an endogenous standard.

\section{Feeding volume assay}

The feeding volume assay was conducted as previously described [32], with minor modifications, on day 39 of Experiment 1. Briefly, hatched Artemia (5 or $60 \mathrm{mg}$ cysts/fish/day) were fed to the zebrafish in a 1.7-L tank as described above. For a blank control, Artemia were placed in a 1.7 -L tank without zebrafish (the tank contained water alone). After $90 \mathrm{~min}$, the number of Artemia not eaten by the zebrafish were counted three times and subtracted from the number in the blank tank to determine the feeding volume in each tank.

\section{Statistical analysis}

All values are presented as means \pm standard error of the mean. Statistical analysis was conducted using analysis of variance followed by Fisher's partial least-squares difference multiple comparison test. Analyses were conducted using STATVIEW for Windows version 5.0 (SAS Institute Inc., Cary, NC, USA). Values of $P<0.05$ were considered statistically significant.

\section{Results}

\section{Food intake}

Visual observation revealed no marked abnormalities or major differences in feeding behavior between the three DIO groups (i.e., DIO, DIO + 0.0025\%GTE, and 
$\mathrm{DIO}+0.0050 \% \mathrm{GTE})$. The ratio of Artemia consumed to the amount of Artemia provided (consumption ratio) was estimated in the feeding volume assay. In male zebrafish, the consumption ratio in the DIO $+0.0025 \%$ GTE $(40 \%)$ and DIO + 0.0050\%GTE (37\%) did not decrease compared with that in the DIO group (24\%). And also in female, the consumption ratio in the $\mathrm{DIO}+0.0025 \% \mathrm{GTE}(33 \%)$ and $\mathrm{DIO}+0.0050 \% \mathrm{GTE}(38 \%)$ did not decrease compared with that in the DIO group (33\%).

\section{Body weight}

Significant increases in body weight were observed within 14 days of the start of the experiment in male and female zebrafish in the DIO group compared with those in the non-DIO group (Figure 2). This trend was maintained throughout the 40-day study. From day 14 onward, exposure to $0.0050 \%$ GTE significantly reduced the diet-induced body weight gain in females $(P<0.05$ or $P<0.01$ compared with the DIO group). By contrast, there were no significant reductions in diet-induced body weight gain in males exposed to either dose of GTE, or in females exposed to $0.0025 \%$ GTE.

\section{Body fat volume}

To quantify body fat volume in DIO zebrafish, we performed 3D micro-CT analysis. This allowed us to quantify the total body fat volume and to separately quantify the visceral and subcutaneous fat volumes. Figure 3 compares the body fat volumes between each experimental group. Total body fat, visceral fat, and subcutaneous fat volumes in both sexes in the DIO group were significantly greater than those in the non-DIO group. Total body fat and visceral fat volumes in male DIO zebrafish were significantly reduced by exposure to $0.0050 \%$ GTE, and those in female DIO zebrafish were significantly reduced by both doses of GTE. However, in both sexes, there were no significant differences in subcutaneous fat volume between the DIO group and either GTEtreated group.

\section{Liver and visceral fat mRNA expression in females}

We analyzed the mRNA expression levels of lipid metabolism genes in the liver and visceral fat tissue of female DIO zebrafish because the suppressive effects of GTE on body fat accumulation were greater in females than in males.

In the liver on day 21 of the experiment, the mRNA expression levels of the mRNAs encoding ACOX1 (a peroxisomal $\beta$-oxidation enzyme), $A C A D M$ (a mitochondrial $\beta$-oxidation enzyme), and PPARA (a nuclear receptor protein that regulates $\beta$-oxidation) were significantly upregulated in the $\mathrm{DIO}+0.0050 \% \mathrm{GTE}$ group compared with the DIO group (Figure 4). By contrast, there was no significant difference in the mRNA
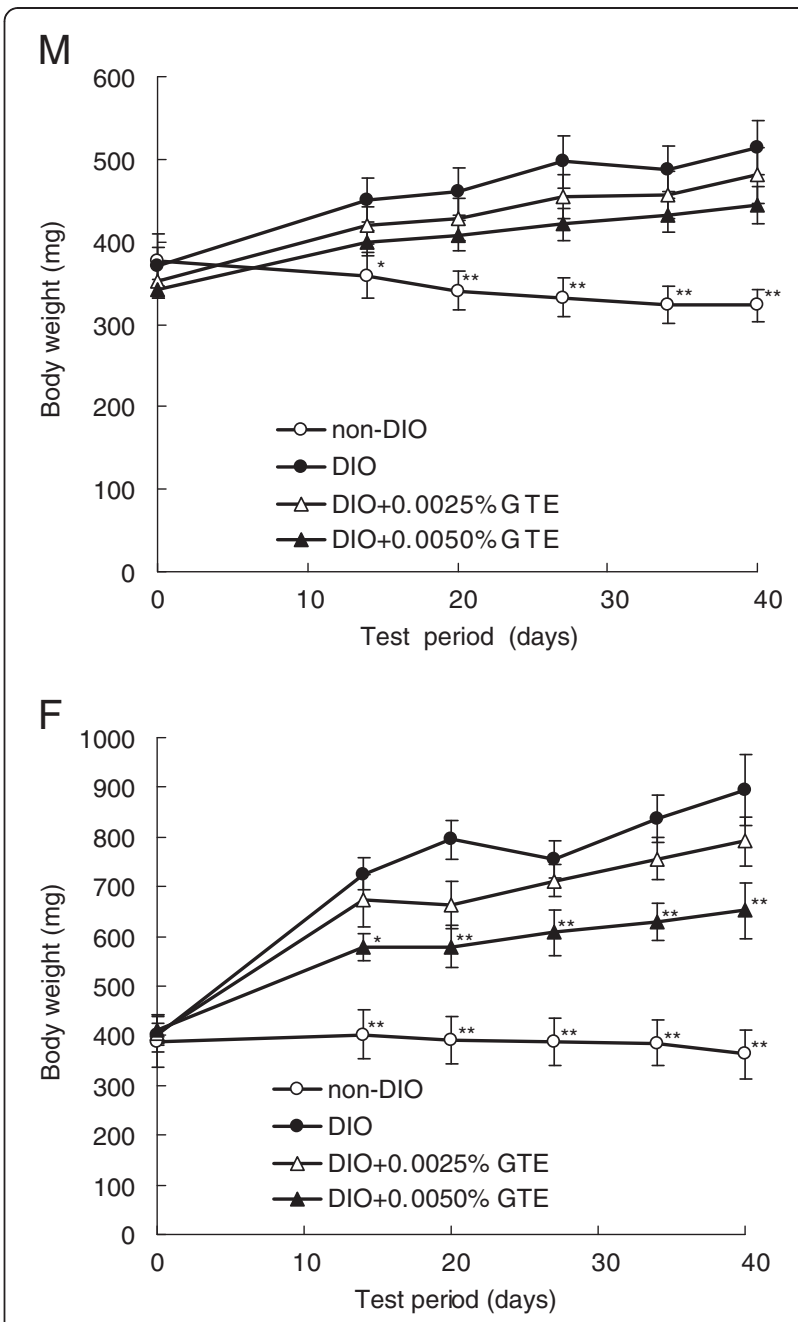

Figure 2 Effects of green tea extract (GTE) on body weight. Changes in body weight in male (M) and female (F) zebrafish. Values are means \pm SE. ${ }^{*} P<0.01$ and ${ }^{*} P<0.05$ vs. the diet-induced obese (DIO) group.

expression of SOCS3 (a protein that suppresses leptin signaling).

In the visceral fat on day 21 of the experiment, the mRNA expression levels of ACOX1, ACADM, and PPARA in the $\mathrm{DIO}+0.0050 \% \mathrm{GTE}$ group were not significantly differ from those in the DIO group. In addition, there were no significant differences in the mRNA expression levels of FASN (fatty acid synthase) or ACC (acetyl-CoA carboxylase), which play important roles in lipogenesis. On the other hand, the mRNA expression of SOCS3 was significantly lower in the $\mathrm{DIO}+0.0050 \% \mathrm{GTE}$ group than in the DIO group (Figure 5).

\section{Discussion}

In this study, we demonstrated that GTE significantly suppressed the accumulation of visceral fat, but not subcutaneous, in a concentration-dependent manner in zebrafish. 

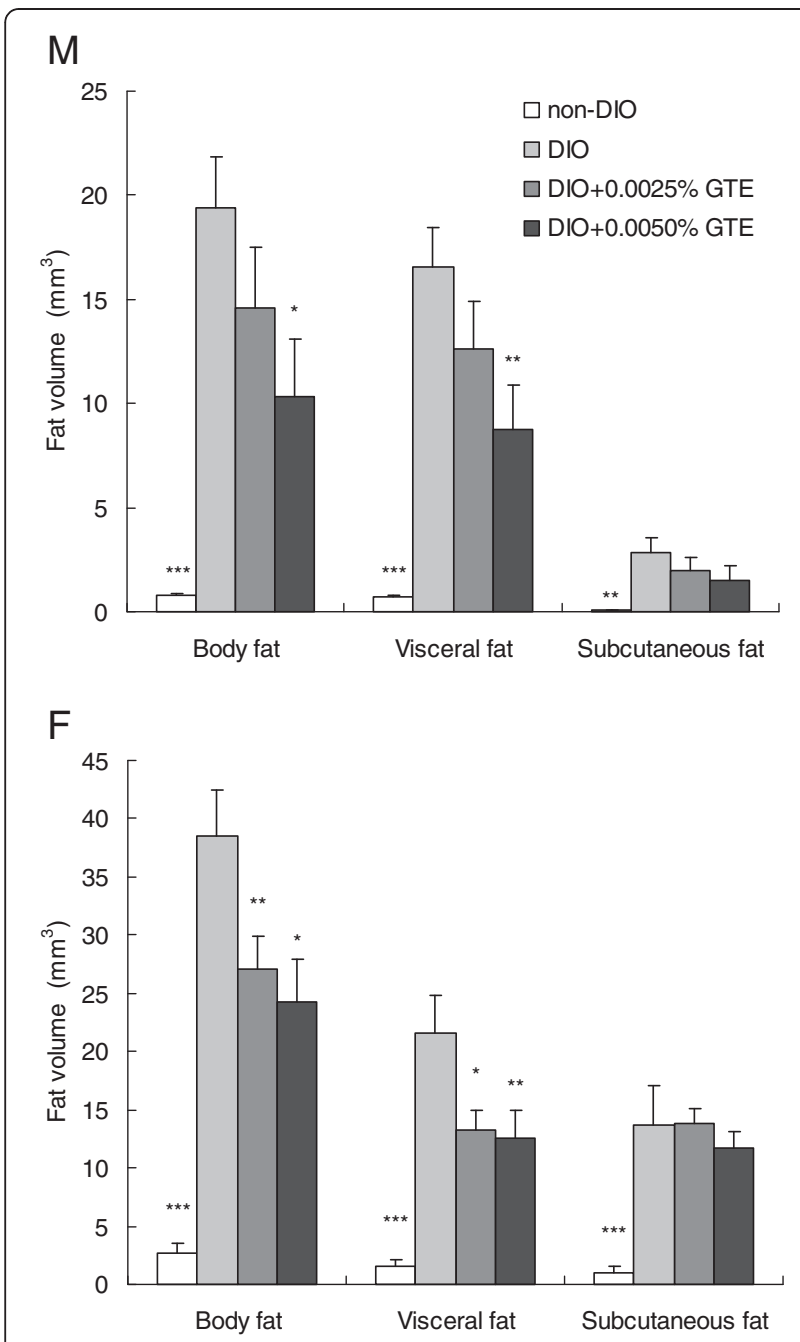

Figure 3 Effects of green tea extract (GTE) on body fat volume. Mean body fat volume in male $(\mathbf{M})$ and female $(\mathbf{F})$ zebrafish after 40 days of feeding. Values are means \pm SE. ${ }^{* * *} P<0.001,{ }^{* *} P<0.01$, and ${ }^{*} P<0.05$ vs. the diet-induced obese (DIO) group.

This effect was accompanied by increase hepatic expression of lipid catabolism genes. These results are very consistent with the findings of previous studies in humans $[12,14]$ and rodents $[10,11,13,14,35-37]$. Although it is unclear whether the functions of visceral and subcutaneous fat in zebrafish are homologous to those in mammals, our findings indicate that body fat distribution is present in zebrafish as well as in humans and animals and that the site-specific effects of GTE are similar to those in mammals.

The mechanisms underlying the suppressive effects of GTE on body fat accumulation have been investigated in rodent models. Some studies have shown that upregulated PPARs and many lipid-metabolizing enzymes stimulate fat oxidation in the liver $[11,35,36]$. The hepatic gene expression pattern observed in DIO zebrafish in our study support these earlier findings. Although it

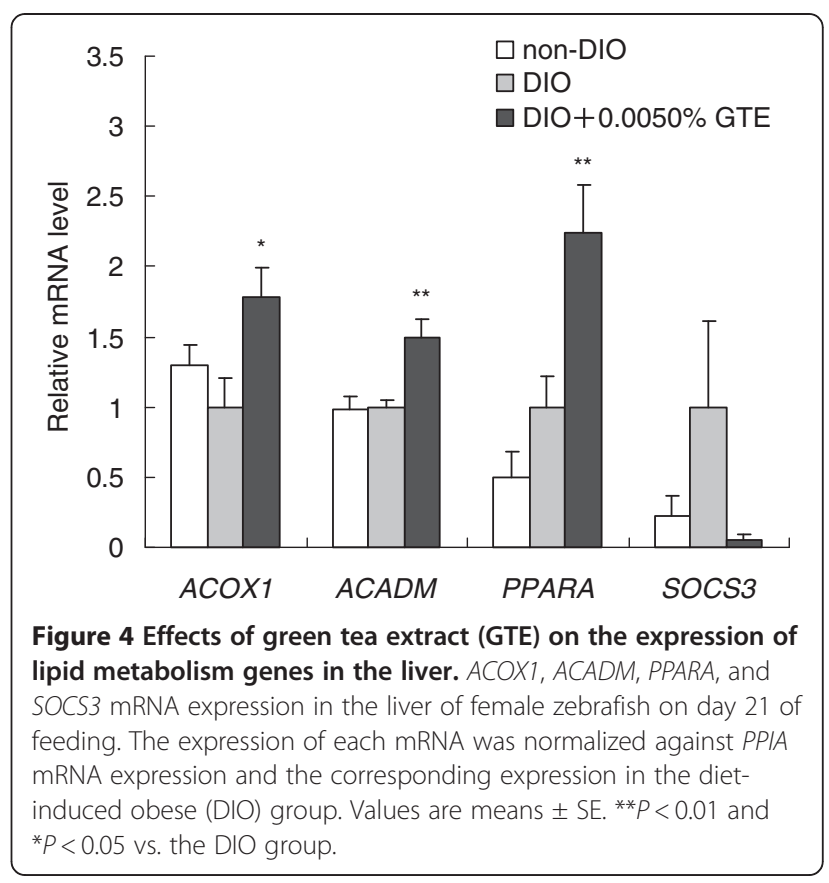

was recently reported that the expression of lipogenic genes, such as $F A S N$, is downregulated in visceral fat tissue in obese mice [38], similar changes were not observed in our study. We assume that the reason for this discrepancy is the difference in obesity models used. In particular, Park et al. used obese mutant mice with increased FASN gene expression in adipose tissue [38], whereas we used a wild-type strain of fish. In support of the hypothesis that the activities of FASN differs between models of obesity, Letexier et al. reported that adipose tissue $F A S N$ expression is not affected by a

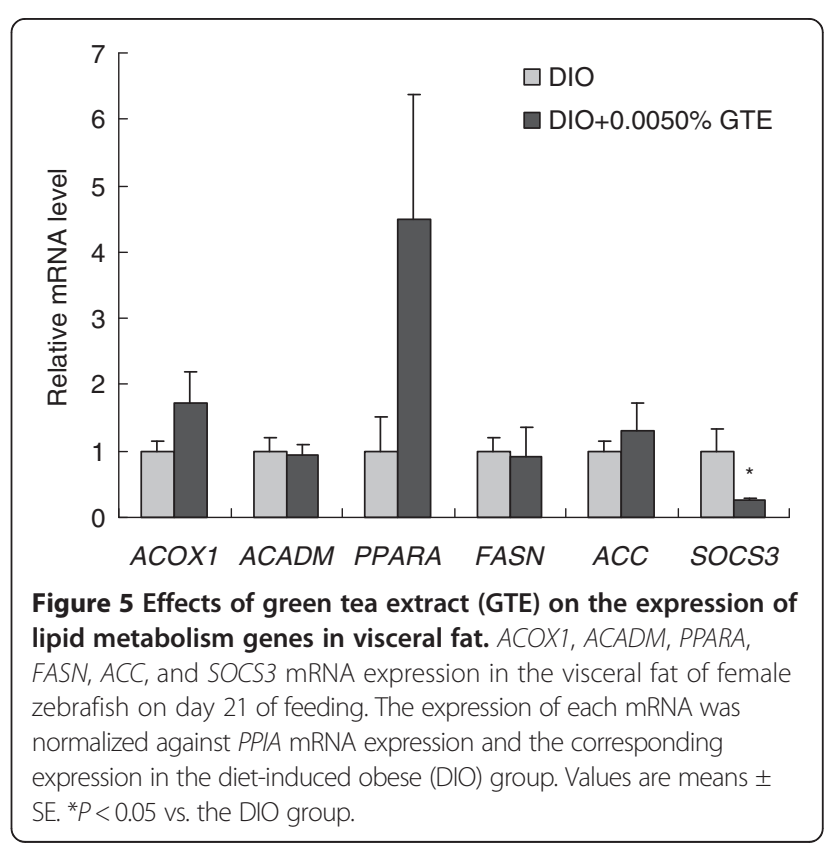


high-fat diet in wild-type rodents and is reduced in obese humans [39]. Their results help support the notion that adipose tissue gene expression profiles differ among species, and the lack of consistency between our data and those of Park et al. Nevertheless, our present results suggest that the mechanism by which GTE suppresses body fat accumulation, at least in the liver, in zebrafish is similar to that in rodents.

We also found that GTE significantly decreased the expression of SOCS3 in the visceral fat of DIO zebrafish. SOCS3 is a negative regulator of leptin signaling and was recently proposed as an important therapeutic target for obesity [40]. SOCS3 production in fat is associated with obesity in humans and rodents as SOCS3 gene expression is increased in subcutaneous fat of obese patients [41], and its protein and gene expression levels are increased in epididymal fat of DIO rodents [42,43]. We found that GTE suppressed adipose tissue SOCS3 expression in zebrafish, which was accompanied by reduced body fat accumulation. To our knowledge, these results suggest for the first time that SOCS3 expression is correlated with body fat volume in zebrafish and is involved in the regulation of body fat volume by GTE.

Another valuable outcome of this study is that 3D micro-CT analysis can be used to analyze the effect of compounds on adiposity in DIO zebrafish. In humans, visceral fat accumulation, unlike subcutaneous fat accumulation, is strongly associated with metabolic and vascular risks, particularly diabetes, hypertension, and stroke, and thus increases the risk of mortality [3]. CT is widely used to measure body fat volume in humans $[44,45]$ and in rodents [46,47]. Although CT is used to evaluate fillet composition in teleosts, such as salmon and carp [48-50], to our knowledge, no reports have used CT to measure body fat volume or visceral/ subcutaneous fat volume in small teleosts. Our data raise the possibility that micro-CT could be used to measure body fat volume in such fish. We believe this technique will play an important role in future studies of lipid metabolism and obesity in zebrafish.

\section{Conclusions}

We showed that GTE significantly inhibits weight gain and body fat accumulation, and alters the expression of hepatic lipid catabolism genes in DIO zebrafish. Our results suggest that GTE exerts beneficial effects on adiposity, possibly by altering the expression of lipid catabolism genes and SOCS3.

\section{Abbreviations}

ACADM: Acyl-coenzyme A dehydrogenase, c-4 to c-12 straight chain gene: ACC: Acetyl-CoA carboxylase gene; ACOX1: Acyl-coenzyme A oxidase 1, palmitoyl gene; AgRP: Agouti-related protein; BMl: Body mass index; $\mathrm{CT}$ : Computed tomography; DIO: Diet-induced obesity; FASN: Fatty acid synthase gene; GTE: Green tea extract; PPARA: Peroxisome proliferator-activated receptor alpha b gene; SOCS3: Suppressor of cytokine signaling $3 b$ gene.

\section{Competing interests}

The authors declare that they have no competing interests.

\section{Authors' contributions}

TH and YS carried out all animal studies. TH drafted the manuscript. JK helped to perform the experiments. YS, NY, MS, TY, and TT conceived the study, participated in its design and coordination, and helped to draft the manuscript. All authors read and approved the final manuscript.

\section{Authors' information}

Takahiro Hasumura is a researcher in the research and development section of Kao Corporation. The focus of Mr. Hasumura's research is health science. Yasuhito Shimada, MD is an assistant professor at the Department of Molecular and Cellular Pharmacology, Pharmacogenomics and Pharmacoinformatics, Graduate School of Medicine, Mie University. The focus of Dr. Shimada's research is the prevention of obesity using zebrafish as a model of diet-induced obesity.

Yuhei Nishimura, MD, PhD is a lecturer in the Department of Molecular and Cellular Pharmacology, Pharmacogenomics and Pharmacoinformatics, Graduate School of Medicine, Mie University. Dr Nishimura's research interests are bioinformatics and pharmacoinformatics.

Toshio Tanaka, MD, PhD is a professor in the Department of Molecular and Cellular Pharmacology, Pharmacogenomics and Pharmacoinformatics, Graduate School of Medicine, Mie University. The focus of Dr Tanaka's research is the identification of drug targets using pharmacogenomic methods. Dr. Tanaka has published more than 100 peer-reviewed research articles and reviews in international journals.

\section{Acknowledgments}

The authors thank Ms. Kimiko Nishiguchi for her technical assistance, Ms. Ai Kamakura for animal breeding and maintenance, and Ms. R. Ikeyama for secretarial assistance. This work was supported, in part, by the Ministry of Education, Culture, Sports, Science and Technology in Japan.

\section{Author details}

${ }^{1}$ Biological Science Laboratories, Kao Corporation, 2606 Akabane, Ichikai-machi, Haga-gun, Tochigi, 321-3497, Japan. ²Department of Molecular and Cellular Pharmacology, Pharmacogenomics and Pharmacoinformatics, Mie University Graduate School of Medicine, 2-174 Edobashi, Tsu, Mie 514-8507, Japan. ${ }^{3}$ Department of Bioinformatics, Mie University Life Science Research Center, 2-174 Edobashi, Tsu, Mie 514-8507, Japan. ${ }^{4}$ Department of Omics Medicine, Mie University Industrial Technology Innovation Institute, 2-174 Edobashi, Tsu, Mie 514-8507, Japan. ${ }^{5}$ Mie University Medical Zebrafish Research Center, 2-174 Edobashi, Tsu, Mie 514-8507, Japan. ${ }^{6}$ Research and Development, Kao Corporation, 2-1-3 Bunka, Sumida-ku, Tokyo 131-8501, Japan.

Received: 18 May 2012 Accepted: 28 July 2012

Published: 7 August 2012

\section{References}

1. Malik VS, Popkin BM, Bray GA, Després JP, Hu FB: Sugar-sweetened beverages, obesity, type 2 diabetes mellitus, and cardiovascular disease risk. Circulation 2010, 121:1356-1364.

2. Spiegelman BM, Flier JS: Obesity and the regulation of energy balance. Cell 2001, 104:531-543.

3. Ibrahim MM: Subcutaneous and visceral adipose tissue: structural and functional differences. Obes Rev 2010, 11:11-18.

4. Kuk JL, Katzmarzyk PT, Nichaman MZ, Church TS, Blair SN, Ross R: Visceral fat is an independent predictor of all-cause mortality in men. Obesity 2006, 14:336-341.

5. Rice-Evans CA, Miller NJ, Paganga G: Structure-antioxidant activity relationships of flavonoids and phenolic acids. Free Rad Biol Med 1996, 20:933-956.

6. Shankar S, Ganapathy S, Srivastava RK: Green tea polyphenols: biology and therapeutic implications in cancer. Front Biosci 2007, 12:4881-4899.

7. Zaveri NT: Green tea and its polyphenolic catechins: medicinal uses in cancer and noncancer applications. Life Sci 2006, 78:2073-2080.

8. Matsumoto N, Ishigaki F, Ishigaki A, Iwashina H, Hara Y: Reduction of blood glucose levels by tea catechin. Biosci. Biotechnol. Biochem 1993 57:525-527. 
9. Miura Y, Chiba T, Tomita I, Koizumi H, Miura S, Umegaki K, Hara Y, Ikeda M, Tomita T: Tea catechins prevent the development of atherosclerosis in apoprotein E-deficient mice. J. Nutr 2001, 131:27-32

10. Klaus S, Pultz S, Thone-Reineke C, Wolfram S: Epigallocatechin gallate attenuates diet-induced obesity in mice by decreasing energy absorption and increasing fat oxidation. Int J Obes 2005, 29:615-623.

11. Murase T, Nagasawa A, Suzuki J, Hase T, Tokimitsu I: Beneficial effects of tea catechins on diet-induced obesity: stimulation of lipid catabolism in the liver. Int J Obes 2002, 26:1459-1464

12. Kozuma K, Chikama A, Hoshino E, Kataoka K, Mori K, Hase T, Katsuragi $Y$, Tokimitsu I, Nakamura H: Effect of intake of a beverage containing 540 mg catechins on the body composition of obese women and men. Prog Med 2005, 25:1945-1957.

13. Nagao $T$, Komine $Y$, Soga $S$, Meguro $S$, Hase $T$, Tanaka $Y$, Tokimitsu I: Ingestion of a tea rich in catechins leads to a reduction in body fat and malondialdehyde-modified LDL in men. Am J Clin Nutr 2005, 81:122-129.

14. Nagao T, Hase T, Tokimitsu I: A green tea extract high in catechins reduces body fat and cardiovascular risks in humans. Obesity 2007, 15:1473-1483.

15. Takase H, Nagao T, Otsuka K, Kozuma K, Kataoka K, Meguro S, Komikado M, Tokimitsu I: Effects of long-term ingestion of tea catechins on visceral fat accumulation and metabolic syndrome: pooling-analysis of 7 randomized controlled trials. Jpn Pharmacol Ther 2008, 36:509-514.

16. Takeshita M, Takashima S, Harada U, Shibata E, Hosoya N, Takase H, Otsuka K, Meguro S, Komikado M, Tokimitsu I: Effects of long-term consumption of tea catechins-enriched beverage with no caffeine on body composition in humans. Jpn Pharmacol Ther 2008, 36:767-776.

17. Zhang Y, Yu Y, Li X, Meguro S, Hayashi S, Katashima M, Yasumasu T, Wang J, Li K: Effects of catechin-enriched green tea beverage on visceral fat loss in adults with a high proportion of visceral fat: a double-blind, placebocontrolled, randomized trial. J Funct Foods 2012, 4:315-322.

18. Dulloo AG, Duret C, Rohrer D, Girardier L, Mensi N, Fathi M, Chantre P, Vandermander J: Efficacy of a green tea extract rich in catechin polyphenols and caffeine in increasing 24-h energy expenditure and fat oxidation in humans. Am J Clin Nutr 1999, 70:1040-1045.

19. Shimotoyodome A, Haramizu S, Inaba M, Murase T, Tokimitsu I: Exercise and green tea extract stimulate fat oxidation and prevent obesity in mice. Med Sci Sports Exerc 2005, 37:1884-1892.

20. Furuyashiki T, Nagayasu H, Aoki Y, Bessho H, Hashimoto T, Kanazawa K, Ashida $\mathrm{H}$ : Tea catechin suppresses adipocyte differentiation accompanied by down-regulation of PPARgamma2 and C/EBPalpha in 3 T3-L1 cells. Biosci Biotech Biochem 2004, 68:2353-2359.

21. Ikeda I, Hamamoto R, Uzu K, Imaizumi K, Nagao K, Yanagita T, Suzuki Y Kobayashi M, Kakuda T: Dietary gallate esters of tea catechins reduce deposition of visceral fat, hepatic triacylglycerol, and activities of hepatic enzymes related to fatty acid synthesis in rats. Biosci Biotech Biochem 2005, 69:1049-1053

22. Watanabe J, Kawabata J, Niki R: Isolation and identification of acetyl-CoA carboxylase inhibitors from green tea (Camellia sinensis). Biosci Biotechnol Biochem 1998, 62:532-534.

23. Best JD, Alderton WK: Zebrafish: an in vivo model for the study of neurological diseases. Neuropsych Dis Treat 2008, 4:567-576.

24. Kishi S, Slack BE, Uchiyama J, Zhdanova IV: Zebrafish as a genetic model in biological and behavioral gerontology: where development meets aging in vertebrates - a mini-review. Gerontology 2009, 55:430-441.

25. Lieschke GJ, Currie PD: Animal models of human disease: zebrafish swim into view. Nat Rev Genet 2007, 8:353-367.

26. Henderson RJ, Tocher DR: The lipid composition and biochemistry of freshwater fish. Prog Lipid Res 1987, 26:281-347.

27. Hölttä-Vuori M, Salo VTV, Nyberg L, Brackmann C, Enejder A, Panula P, Ikonen E: Zebrafish: gaining popularity in lipid research. Biochem J 2010, 429:235-242.

28. Morais S, Knoll-Gellida A, André M, Barthe C, Babin PJ: Conserved expression of alternative splicing variants of peroxisomal acyl-CoA oxidase 1 in vertebrates and developmental and nutritional regulation in fish. Physiol Genom 2007, 28:239-252.

29. Song Y, Cone RD: Creation of a genetic model of obesity in a teleost. FASEB J 2007, 21:2042-2049.

30. Stoletov K, Fang L, Choi SH, Hartvigsen K, Hansen LF, Hall C, Pattison J, Juliano J, Miller ER, Almazan F, Crosier P, Witztum JL, Klemke RL, Miller YI: Vascular lipid accumulation, lipoprotein oxidation, and macrophage lipid uptake in hypercholesterolemic zebrafish. Circ Res 2009, 104:952-960.
31. Oka T, Nishimura Y, Zang L, Hirano M, Shimada Y, Wang Z, Umemoto N, Kuroyanagi J, Nishimura N, Tanaka T: Diet-induced obesity in zebrafish shares common pathophysiological pathways with mammalian obesity. BMC Physiol 2010, 10:21.

32. Tainaka T, Shimada Y, Kuroyanagi J, Zang L, Oka T, Nishimura Y, Nishimura N, Tanaka T: Transcriptome analysis of anti-fatty liver action by Campari tomato using a zebrafish diet-induced obesity model. Nutr Metab 2011, 8:88.

33. Murase T, Haramizu S, Shimotoyodome A, Tokimitsu I, Hase T: Green tea extract improves running endurance in mice by stimulating lipid utilization during exercise. Am J Physiol Reg Integr Comp Physiol 2006, 290:R1550-R1556.

34. Westerfield M: A guide for the laboratory use of zebrafish (Danio rerio). Eugene: University of Oregon Press; 2007.

35. Chen N, Bezzina R, Hinch E, Lewandowski PA, Cameron-Smith D, Mathai ML, Jois M, Sinclair AJ, Begg DP, Wark JD, Weisinger HS, Weisinger RS: Green tea, black tea, and epigallocatechin modify body composition, improve glucose tolerance, and differentially alter metabolic gene expression in rats fed a high-fat diet. Nutr Res 2009, 29:784-793.

36. Lee MS, Kim CT, Kim Y: Green tea (-)-epigallocatechin-3-gallate reduces body weight with regulation of multiple genes expression in adipose tissue of diet-induced obese mice. Ann Nutr Metab 2009, 54:151-157.

37. Sae-Tan S, Grove KA, Lambert JD: Weight control and prevention of metabolic syndrome by green tea. Pharmacol Res 2011, 64:146-154.

38. Park HJ, DiNatale DA, Chung MY, Park YK, Lee JY, Koo SI, O'Connor M, Manautou JE, Bruno RS: Green tea extract attenuates hepatic steatosis by decreasing adipose lipogenesis and enhancing hepatic antioxidant defenses in ob/ob mice. J Nutr Biochem 2011, 22:393-400.

39. Letexier D, Pinteur C, Large V, Fréring V, Beylot M: Comparison of the expression and activity of the lipogenic pathway in human and rat adipose tissue. J Lipid Res 2003, 44:2127-2134.

40. Howard JK, Cave BJ, Oksanen LJ, Tzameli I, Bjoørbæk C, Flier JS: Enhanced leptin sensitivity and attenuation of diet-induced obesity in mice with haploinsufficiency of Socs3. Nat Med 2004, 10:734-738.

41. Rieusset J, Bouzakri K, Chevillotte E, Ricard N, Jacquet D, Bastard JP, Laville M, Vidal H: Suppressor of cytokine signaling 3 expression and insulin resistance in skeletal muscle of obese and type 2 diabetic patients. Diabetes 2004, 53:2232-2241.

42. Kanatani Y, Usui I, Ishizuka K, Bukhari A, Fujisaka S, Urakaze M, Haruta T, Kishimoto T, Naka T, Kobayashi M: Effects of pioglitazone on suppressor of cytokine signaling 3 expression: potential mechanisms for its effects on insulin sensitivity and adiponectin expression. Diabetes 2007, 56:795-803.

43. Gu H, Liu L, Ma S, Liu Y, Ren Y, Zhai L, Yu F, An L, Yang J: Inhibition of SOCS-3 in adipocytes of rats with diet-induced obesity increases leptinmediated fatty acid oxidation. Endocrine 2009, 36:546-554

44. Cnop M, Havel PJ, Utzschneider KM, Carr DB, Sinha MK, Boyko EJ, Retzlaff BM, Knopp RH, Brunzell JD, Kahn SE: Relationship of adiponectin to body fat distribution, insulin sensitivity and plasma lipoproteins: evidence for independent roles of age and sex. Diabetologia 2003, 46:459-469.

45. Matsuzawa $Y$, Nakamura T, Takahashi M, Ryo M, Inoue S, Ikeda Y, Ohno M, Sakata T, Fukagawa K, Saitoh Y, Sato Y, Shirai K, Miyazaki S, Tokunaga K, Yamanouchi K, Takahashi M, Shibasaki T, Nagai M: New criteria for 'obesity disease' in Japan. Circ J 2002, 66:987-992.

46. Judex S, Luu YK, Ozcivici E, Adler B, Lublinsky S, Rubin CT: Quantification of adiposity in small rodents using micro-CT. Methods 2010, 50:14-19.

47. Luu YK, Lublinsky S, Ozcivici E, Capilla E, Pessin JE, Rubin CT, Judex S: In vivo quantification of subcutaneous and visceral adiposity by micro-computed tomography in a small animal model. Med Eng Phys 2009, 31:34-41.

48. Folkestad A, Wold JP, Rørvik KA, Tschudi J, Haugholt KH, Kolstad K, Mørkøre T: Rapid and non-invasive measurements of fat and pigment concentrations in live and slaughtered Atlantic salmon (Salmo salar L.). Aquaculture 2008, 280:129-135.

49. Nanton DA, Vegusdal A, Rørå AMB, Ruyter B, Baeverfjord G, Torstensen BE: Muscle lipid storage pattern, composition, and adipocyte distribution in different parts of Atlantic salmon (Salmo salar) fed fish oil and vegetable oil. Aquaculture 2007, 265:230-243.

50. Romvári R, Hancz CS, Petrási ZS, Molnár T, Horn P: Non-invasive measurement of fillet composition of four freshwater fish species by computer tomography. Aquacult Int 2002, 10:231-240.

doi:10.1186/1743-7075-9-73

Cite this article as: Hasumura et al:: Green tea extract suppresses adiposity and affects the expression of lipid metabolism genes in dietinduced obese zebrafish. Nutrition \& Metabolism 2012 9:73. 